\title{
Electrical Injuries: The Iceberg Phenomena
}

\author{
Krishna Manandhar, Jayan Man Shrestha, Sangam Rayamajhi, Ishwar Lohani \\ Department of Plastic Surgery and Burns, Tribhuvan University Teaching Hospital, Kathmandu, Nepal \\ Correspondence: Dr. Krishna Manandhar, Department of Plastic Surgery and Burns, TUTH, Kathmandu, Nepal
}

\begin{abstract}
Introduction: The deceptive nature of electrical injury is likened to an iceberg phenomenon. Whether the tissue is conductive or resistant both are injured due to electroporation and heat, respectively. The objective of the study is to evaluate the types and pattern of injuries and attempt to predict the chances of various types of injuries and highlight the iceberg phenomenon.

Methods: A retrospective study includes 36 patients. Injuries were classified into superficial and deep. Total burned surface area (TBSA) was categorized into four, $</=5 \%, 6$ to $10 \%, 11$ to $20 \%$, and $>20 \%$. The depth of injury was categorized into superficial and deep. Deep injuries were elaborated into loss of skin, muscle, tendon, nerve, artery, cartilage and damage of bone and internal organs. Treatment was grouped into conservative and surgical, where surgical was classified into minor, major and amputation procedures.

Results: Injuries were mostly located over the upper extremities $(47.76 \%)$. The first TBSA category had the highest number of patients $(64 \%)$, highest percent of superficial and deep injuries $(63.88 \%$ and $61.29 \%$, respectively) and highest percentage of procedures $(64.25 \%)$. The average number of procedures per patient was 3.8. The median burned surface area (BSA) was $4 \%$ and most of the procedures were performed in patients with less than $4 \% \mathrm{BSA}$.

Conclusion: Electrical injuries are truly iceberg phenomenon where a small area of TBSA hides the greatest percentage of the deep structure injuries and brings about surprising reconstructive challenges.
\end{abstract}

Key Words: Amputations; Debridement; Electrical injury; Reconstructive flaps; Skin grafting.

\section{Introduction}

Electrical injuries is one of the most deceptive of injuries where the phenotype of the injury may seem very inconspicuous and fool even the experts but the detailed internal effects may surprise even the most attentive, like an iceberg might fool the captain of the ship who can see only the tip. They are the fourth leading cause of workrelated traumatic death in US $(5-6 \%$ of all workers' deaths). ${ }^{1}$ Electrocutions at home account for more than two hundred deaths per year. ${ }^{2}$

The pathophysiological effects of electrical current differ with its intensity. The maximum current an adult can grasp and "let go"is $16 \mathrm{~mA}$, while for a child is $5 \mathrm{~mA}$. Higher intensity may cause tetany of skeletal muscles, paralysis of respiratory muscles and respiratory arrest, ventricular fibrillation and asystole..$^{3-5}$

There are certain factors that determine the extent of injury. They are intensity of the current, duration of contact and pathway of the current. According to Ohm's law, current = voltage/resistance. ${ }^{3}$ It is very important to understand that a tissue having high conductivity will suffer damage due to electroporation, which is an effect where cell membranes are disrupted without causing significant heating because of current flow and tissue can be damaged in the absence of burns, conversely, a tissue having low conductivity needs itself to increase its temperature to be conductive, developing high resistance, and thus will also suffer damage 
due to the heat energy created. ${ }^{6-7}$ This is like a double edge sword phenomenon, neither conductivity nor resistance benefits the overall status. Resistance is least in nerves, blood, mucous membranes, and muscles; the highest resistance in bones, fat, and tendons. Skin has intermediate as well as variable resistance, whether it is dry or wet, thin or thick. ${ }^{5}$ Koumbourlis explained that there is an external resistance that is provided by the skin and the internal provided by the internal organs. ${ }^{8}$ The skin depending on its characteristics like moisture and thickness may be able to change its electrical properties and therefore result in different consequences. ${ }^{3,4,9}$ If the contact is brief, electrical field mechanism will likely be the cause of the damage, but in longer contact duration heating mechanism will be the more important cause of the damage. ${ }^{9}$ The determination of the electrical pathway is important both for acute management and for overall prognosis. A vertical pathway parallel to the axis of the body involves virtually all the vital organs. A horizontal pathway from hand to hand will spare the brain but can still be fatal due to involvement of the heart, respiratory muscles, or spinal cord. ${ }^{10-16}$ A pathway through the lower part of the body may cause severe local damage but will probably not be lethal. ${ }^{10}$

Here, in this retrospective study, in Tribhuvan University Teaching Hospital (TUTH) between April $14^{\text {th }} 2014$ to April 12 2016 (2070-2072 B.S.), we evaluate the types and pattern of injuries and attempt to predict the chances of various types of injuries and highlight the iceberg phenomenon.

\section{Methods}

Forty patients presented to the department of plastic surgery and burns in TUTH, with electrical injuries and underwent appropriate management. One patient died during the course of the treatment. Three patients had sustained flash injury simultaneously and were excluded from the study as only those who sustained "electrical injury" were included. All injuries are declared during the operation.

The injuries were classified somewhat similar as for flame injury according to the depth and total burned surface area.Total burned surface area (TBSA) was categorized into four, first is $</=5 \%$, second between 6 to $10 \%$, third between 11 to $20 \%$, and fourth $>20 \%$. The depth of injury was categorized into superficial and deep. Injuries were considered superficial if the deeper parts of the dermis still remained intact, while injuries where complete loss of skin layer and/or involvement of deeper structures were present were considered deep injuries.
All patients underwent emergency resuscitative protocols as per the international guidelines of clinical assessment, fluid resuscitation, oxygenation, total burnt surface area determination, monitoring and dressings and operations.

The treatment methods were grouped into two categories, conservative (non-surgical) and surgical management. Patients undergoing conservative management underwent dressing. Surgical management was classified into 3 groups of procedures, minor, major and amputation. Minor groups were those who underwent debridement and split thickness skin grafting. Major groups were those who underwent reconstructive procedures with or without minor procedures. Amputations were classified according to the number of structures individually amputated. For example, a digital amputation would be counted as one amputation, two digits as two amputations, but a whole hand amputation or a whole upper limb amputation would be counted also as one. Another example where a patient having to undergo major flap reconstruction and skin grafting procedures would be considered to have major as well as minor procedures.

\section{Results}

All patients were from different economical background, and some were electricians by profession. The types of source were both household and high voltage.

The age of the patients ranged from youngest of eight years to the eldest of fifty-five years. Out of 36 included patients, 24 of them aged within thirty years, about $66 \%$, $10(27.77 \%)$ were between the thirties to fifties. Males constituted about $72 \%$ (26) and remaining $28 \%$ (10). Out of 36 patients the number of sites injured was 67 . Majority of the injury were related to the upper extremity, $47.76 \%$ (32), whereas to the lower extremity, $20.89 \%$ (14), to abdomen and trunk constituted $16.41 \%(11)$, to head and neck injury occurred in $14.92 \%(10)$, and to the internal organs (intraabdominal organs) in $1.49 \%$ (1). Out of 36 patients with respect to TBSA, $23(64 \%)$ fitted into the first category, 7 $(19 \%)$ constituted the second category, $4(11 \%)$ the third category, and $2(6 \%)$ in the fourth category.

All patients sustained superficial injuries, 36 (100\%), and majority of them, $31(86.10 \%)$ sustained deep injuries. The total number of deep structures damaged in 31 patients was 111 , among which skin loss dominated the scene, $31(28 \%)$, muscle injury accounting for second most injured structure, $19,(17 \%)$, tendon taking third place, 17 $(15 \%)$, then nerve $14(13 \%)$, then artery, $12(14 \%)$, bone, $10(9 \%)$, cartilage $5(4 \%)$, and at last the internal organs, 
renal failure, $3(\sim 3 \%)$. From the total number of patients (36), skin loss was present in 31 (86.11\%), muscle in 19 $(52.77 \%)$, tendon in $17(47.22 \%)$, nerves in $14(38.88 \%)$, arteries in $12(33.33 \%)$, bone in $10(27.77 \%)$, cartilage in $5(13.88 \%)$ and internal organs in $3(8.33 \%)$ in patients. (Figure 1)

Correlating the TBSA categories and superficial and deep injuries, majority of patients with both superficial and deep injuries fell in to the first category, 23 (63.88\%) and $19(61.29 \%)$, respectively. TBSA second category had $7(19.44 \%)$ and $6(19.35 \%)$, respectively, TBSA third category had $4(11.11 \%)$ and $4(12.90 \%)$, respectively, and the fourth category accounted for $2(5.55 \%)$ and $2(6.45 \%)$.

Correlating TBSA categories and differential deep structures injury most of the patients having maximum number for any given tissue fall in the first TBSA category. (Figure 2) Majority of patients with skin loss fall into the first TBSA category, and were 19 (61.29\%). Similarly, most of these patients with muscle loss fall into the first TBSA category, 10 (52.63\%). Eight $(47.05 \%)$ of patients with tendon injury also fall into the first TBSA category. Among patients with the nerve injury most of them fall into the first TBSA category, $7(50 \%)$. Fifty percent of patients with arterial injury fall into the first TBSA category. Most of the patients with cartilage injury fall into the first TBSA category, 2 (40\%). Among patients with internal organ injury, the first, second and fourth TBSA categories shared $1(33.33 \%)$ each. Similarly, among patients with bone injury, the first, second and third TBSA categories shared $3(30 \%)$ each. The $p$ value was significant, $<0.05$, in only bone injury.

Out of 36 patients, six underwent conservative management with dressings and were excluded from the procedure count. Majority of the patients that were treated conservatively or operatively fitted into the first TBSA category, conservative was $4(66.67 \%)$, minor was $17(65.58 \%)$, major was 14 (73.68\%) and amputations were $5(50 \%)$. More than $64 \%$ of the procedures were performed in the patients within the first TBSA category. In the fourth category, comprising of only 2 patients, one died and another did not require major operations. (Figure 3) In 30 patients, a total of 137 procedures were performed with average of 4.56 (137/30), but overall average procedures per admitted patient were 3.8 (137/36). Evaluating the groups of procedures and their quantity, the actual number of patients receiving operations was 55, where any given patient might be receiving all three groups of procedures, minor, major and amputation, constituted $47 \%, 35 \%$ and $18 \%$, respectively. (Figure 3) Patient receiving minor operation required at least 2.61 procedures, while those receiving major operation and amputation required at least 2.89 and 1.4 procedures, respectively. For each patient admitted, it is calculated that one underwent at least 1.88 minor, 1.52 major, and 0.38 amputation procedures. Patients receiving minor operations were $72.22 \%$, patients receiving major procedures were $52.77 \%$, while $27.77 \%$ underwent amputation procedure. With respect to these procedures, more than fifty percent were major and amputation procedures, 40.14\%, and $10.21 \%$, respectively, while minor constituted nearly fifty percent $(49.63 \%)$. (Figure 3, 4)

The median of overall total burned surface area was $4 \%$. Sixty percent (18) of the operated patients grouped in $<4 \%$.

The median numbers of procedures for each TBSA category are 3 for first, 4 for second and more than 6 for third. The median numbers of minor procedures per category was 2 for first, 2 for second, 4 for third and 2 for fourth. The median numbers of major procedures per category was 3 for first, 3 for second, 2 for third.

Out of 30 operated patients, 10 underwent amputation procedures. The first TBSA category had 5 patients, second had 2 and third had 3 . Ten patients underwent 14 amputation procedures, from which 6 were performed in the first TBSA category, 3 were performed in second and 5 in the third. (Table 1)

\section{Discussion}

Most of the patients are of very young age, less than 30 years, about $70 \%$, while $60 \%$ are victim at the most productive years, which might be a huge burden to the family if the patient is the only person responsible as bread earner. It also very obvious as in our society that males are the ones who usually dare to handle electrical matters at home or at work and therefore are the majority of the victims. It is more debilitating if hands are subjected to injury and more if they require extensive surgery as are majority of our patients, more than $62 \%$, and moreover, in their productive independent years. Fortunately, there are very few patients with internal injuries that would be fatal otherwise.

In a five-year epidemiological and outcome analytical retrospective study performed in a major burn center in Southwest China of 6325 burn patients in 2017 it was reported to have male-female ratio of $1.3: 1,2.8: 1$ in flame and scald injuries, but very high ratios of $8.6: 1$ in electrical injuries. ${ }^{17}$ It also reported that significant percentage of patients were between 0 to 6 years of age in scald and flame 
burns but in electrical injuries, most of their patients were between 21 to 60 years of age which to some extent also matches to our findings.

Upper limb injuries contribute to most of the injuries. Some have reported lesser hand injuries in flame and scald injuries but with respect to electrical injuries where most of the injury are located over the upper limbs. ${ }^{17}$ Our study also has similar findings. Unlike the injuries caused by other types of causes like the flame or scald burns, electrical causes tend to have lesser TBSA and as we can see in our findings as well as those in Southwest China. ${ }^{17}$ In this Chinese report, first, $95.5 \%$ of electrical injury resulted in full thickness burns which also corresponds to our findings of $86.1 \% .{ }^{17}$ Second, they reported that majority of their patients who sustained full thickness electrical injury were in less than or equal to 5\% TBSA group, that is, $76.01 \%$. Our study showed almost similar results where $61.29 \%$ of patients who sustained deep injury were in first category. Third, they reported that $21 \%$ of scald, $41.6 \%$ of flame, $78.2 \%$ of contact burns had full thickness injury as compared to $95.5 \%$ in electrical injury which shows that electrical injuries results is more deeper injuries than types of burns and despite a small area of TBSA the degree or depth of injury is greater proportionately in electrical injury as that would have been observed in flame or scald injuries. Hussmann et al found that these incidents were more found in high voltage causes.

The variety of injury and the reconstructive operations needed and also the predictability of injury of tissues in case of electrical accident are astounding. The chances of such deep injuries, especially internal organs like eyes, liver, central nervous system, and renal failures have also been reported. ${ }^{18}$ In our findings structures injured ranges from the skin to the bone and internal organs. Such findings signifies the very distinctive feature of the electrical injury where very little is visible from the outside and plenty hidden inside like the iceberg in the sea. Other authors have also reported that their patients had full thickness burns primarily concentrated in $5 \%$ or less TBSA $(67.5 \%, 1,709 / 2,536)$ and $1 \%$ TBSA in particular $(33.6 \%$, $851 / 2,536) .{ }^{17}$

The extent of injury of the skin with complete loss is overwhelming. Although electrical burns often appear to be less impressive than flame burns on the surface, appearance cannot be used to predict the severity of injury. ${ }^{19}$ Other studies have also shown the extent of full thickness injury in $95.5 \%$ with more common in patients who has first TBSA category. ${ }^{17}$ This clearly signifies that despite the visible small TBSA the magnitude of injury deep within is significantly large, likened to the iceberg phenomenon.
The muscle injury also is relatively frequent. We have found more than $52 \%$ of total electrical injury have had muscle injury, while only $17 \%$ from total number of deep injured structures $(n=111)$. Most of the injury occurred in patients in the first TBSA category (52.63\%), which shows again a very much of iceberg phenomena. Such an injury with respect to extremities has very debilitating consequences, which were very obvious in patients included in our study. On microscopy of excised muscle tissue there were spotty destruction of muscles with healthy fibers adjacent and such an existence of dead and the living together in the same field is more destructive to the living. ${ }^{20}$

Tendons were also not spared from injury along with their muscle counterparts and comprising more than $47 \%$ of total patients, fifteen percent $(15 \%)$ of total number of deep structures involved, more than $47 \%$ fell in to TBSA first category, which also gives us an impression the lesser the outside injury, comparatively, greater the injury deep within, just like an iceberg phenomenon.

Surprisingly, we found less nerve injury than expected considering its electricity conduction properties. Nevertheless, thirty eight (38\%) from total number of patients sustained severe nerve injury requiring excision and repair later, thirteen percent $(13 \%)$ of total number of deep structures involved, more than $50 \%$ fell in to the first TBSA category, again providing us an idea to not to underestimate the minor TBSA injuries where there might highly possible chances of nerve injury underneath.

Another probably easily expected injury is the arterial. In angiographic findings of patients with electrical injury there was severe occlusive arterial damage in 38 out of 52 angiograms of extremities (73.07\%). ${ }^{21}$ In our study, more than $33 \%$ of patients had arterial injury, eleven percent (11\%) from total number of deep structures involved, and fifty percent $(50 \%)$ were in the first TBSA category. This also gives us some ideas about deceptive small TBSA injury covering up gross arterial injury and suggest us an indication to perform angiography of the extremities affected despite minor TBSA injury. On microscopy it was shown damaged and normal small vessels occur in the same microscopic field which maybe the reason for slow demarcation of non-viable tissues. ${ }^{20}$

Three patients $(13.88 \%)$ who is said to have cartilage injury are those who sustained external ear injury. All these patients required debridement and excision of the cartilage. Such injuries were associated with injury if the underlying bone and muscles and nearby scalp tissue. Little has been written of such injuries in the literature. 


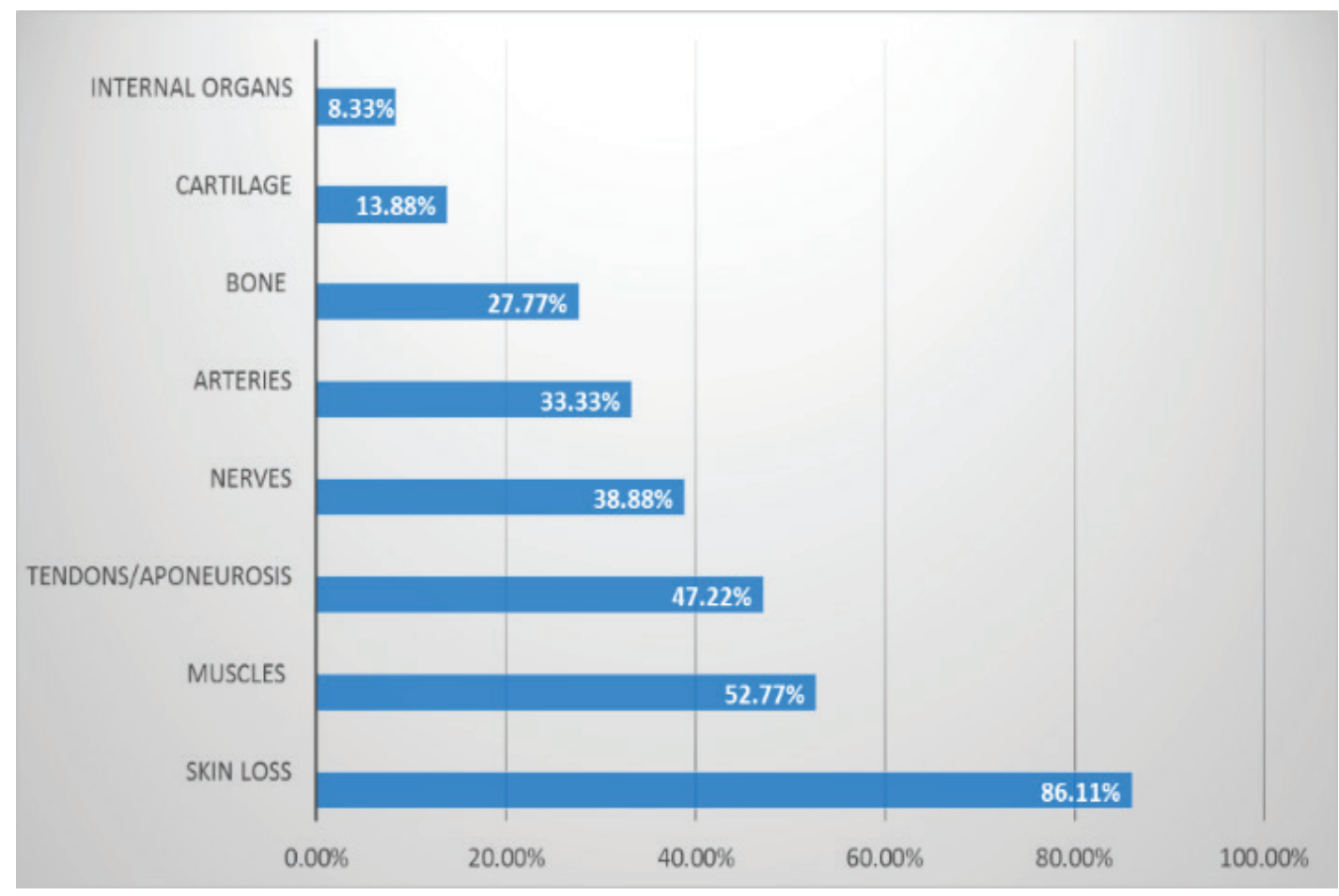

Figure 1: Differential deep structure injury vs total number of patients

$70.00 \%$

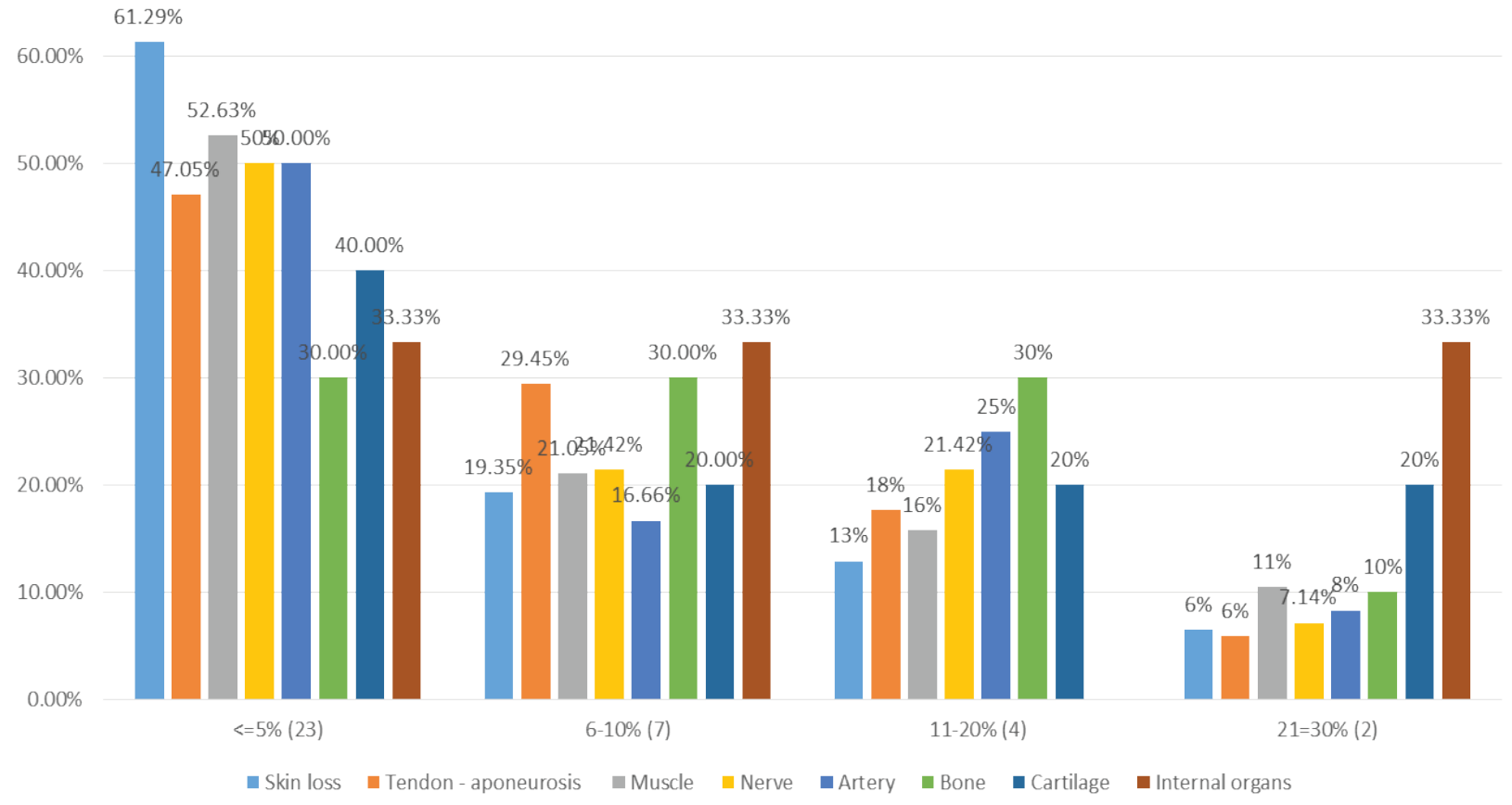

Figure 2: Patients with differential deep structures damage per TBSA category 
Table 1: Distribution of patients in accordance with management

\begin{tabular}{|l|l|l|l|l|l|l|}
\hline $\begin{array}{l}\text { Procedure (Pr) } \\
\text { group (Prn = } \\
\text { 137) }\end{array}$ & $\begin{array}{l}\text { No of } \\
\text { operated } \\
\text { patients } \\
\text { (Opn) }\end{array}$ & No $\mathbf{P r}(\mathbf{P n})$ & Pn/Opn & $\begin{array}{l}\text { Pn/n } \\
(36)\end{array}$ & $\begin{array}{l}\text { \% of each } \\
\text { group of Pr } \\
\text { (Prn/n) }\end{array}$ & $\begin{array}{l}\text { Relative \% of patients } \\
\text { receiving each group of } \\
\operatorname{Pr}(\text { Opn/n) }\end{array}$ \\
\hline Minor & $26(47 \%)$ & 68 & 2.61 & 1.88 & 49.635 & 72.22 \\
\hline Major & $19(35 \%)$ & 55 & 2.89 & 1.52 & 40.145 & 52.77 \\
\hline Amputation & $10(18 \%)$ & 14 & 1.4 & 0.38 & 10.218 & 27.77 \\
\hline
\end{tabular}

Management Distribution and Burn Surface Area

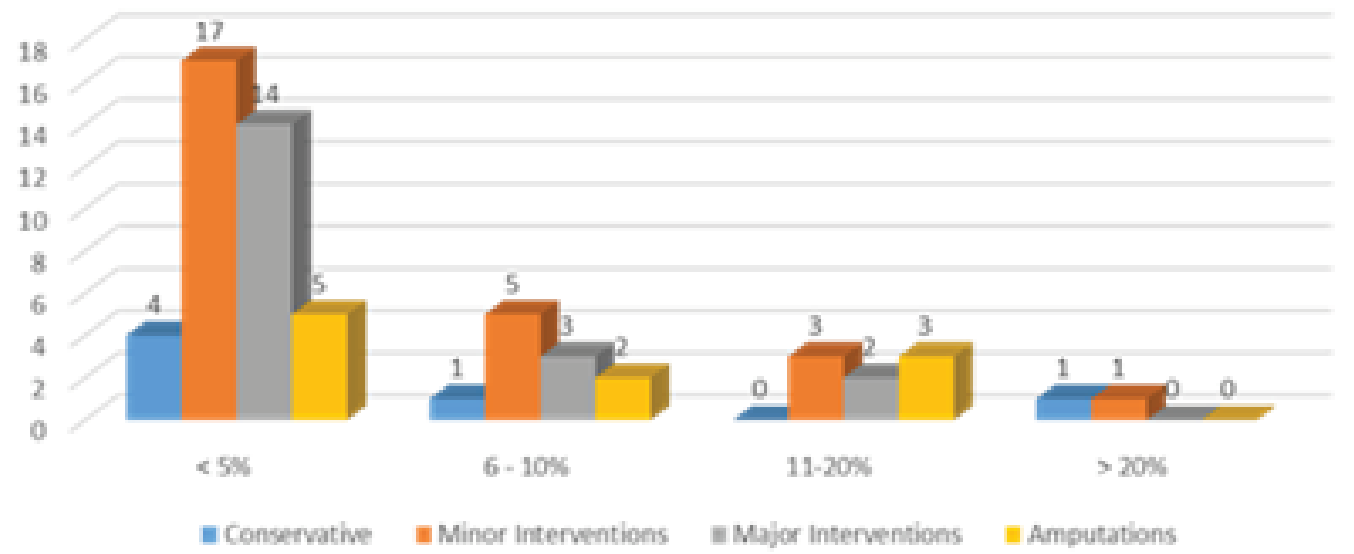

Figure 3: Details of procedures, actual number of operated patients, and their relationship with overall number of patients

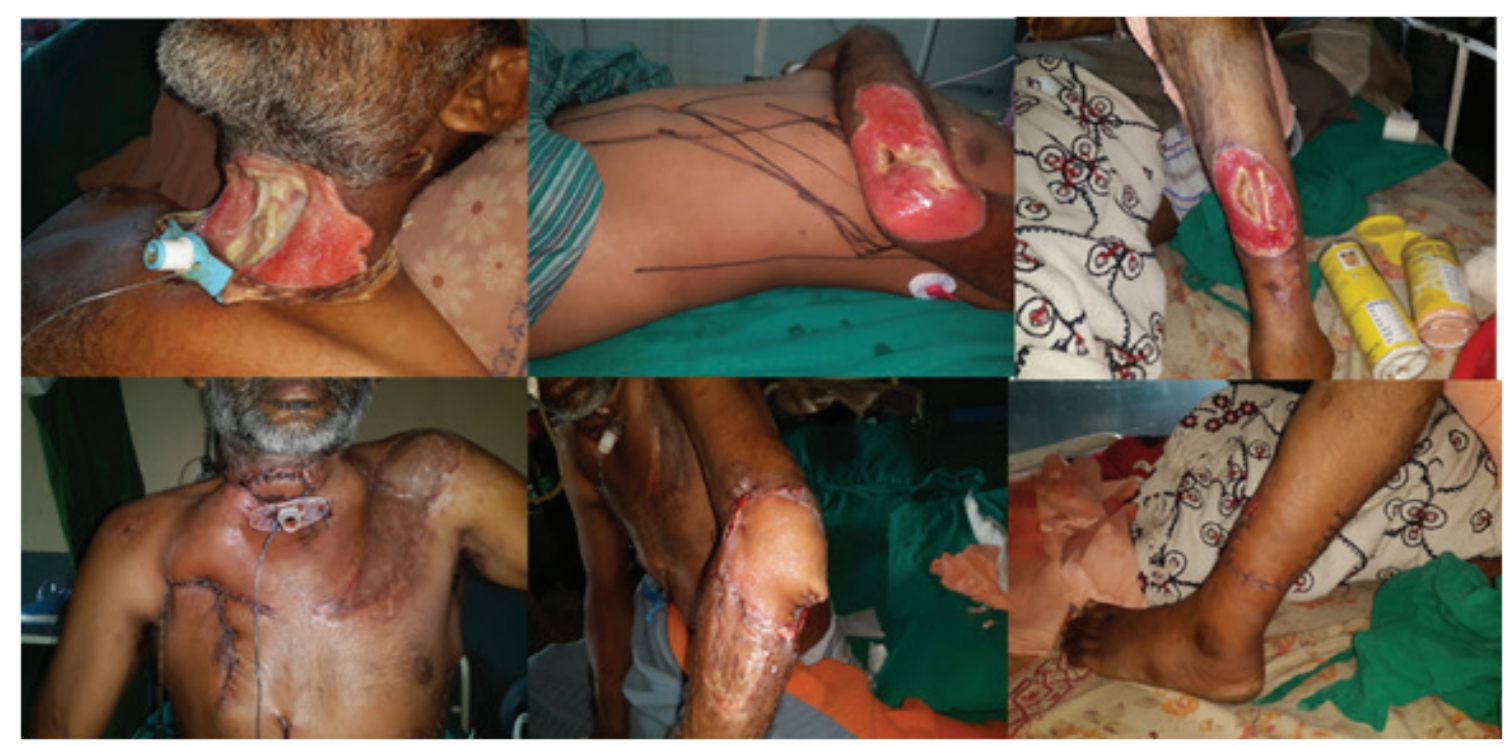

Example 1. This is a male of 56 years who sustained electrical injury at multiple places. The TBSA was $7 \%$ over the neck, left upper and lower limbs. Neck injury resulted in need for lagynectomy and tracheostomy and coverage of the defect by bilateral deltopectoral flaps. Upper limb defect required thoraco-abdominal flap and skin graft. The leg defect was treated with transposition flap and skin graft. 


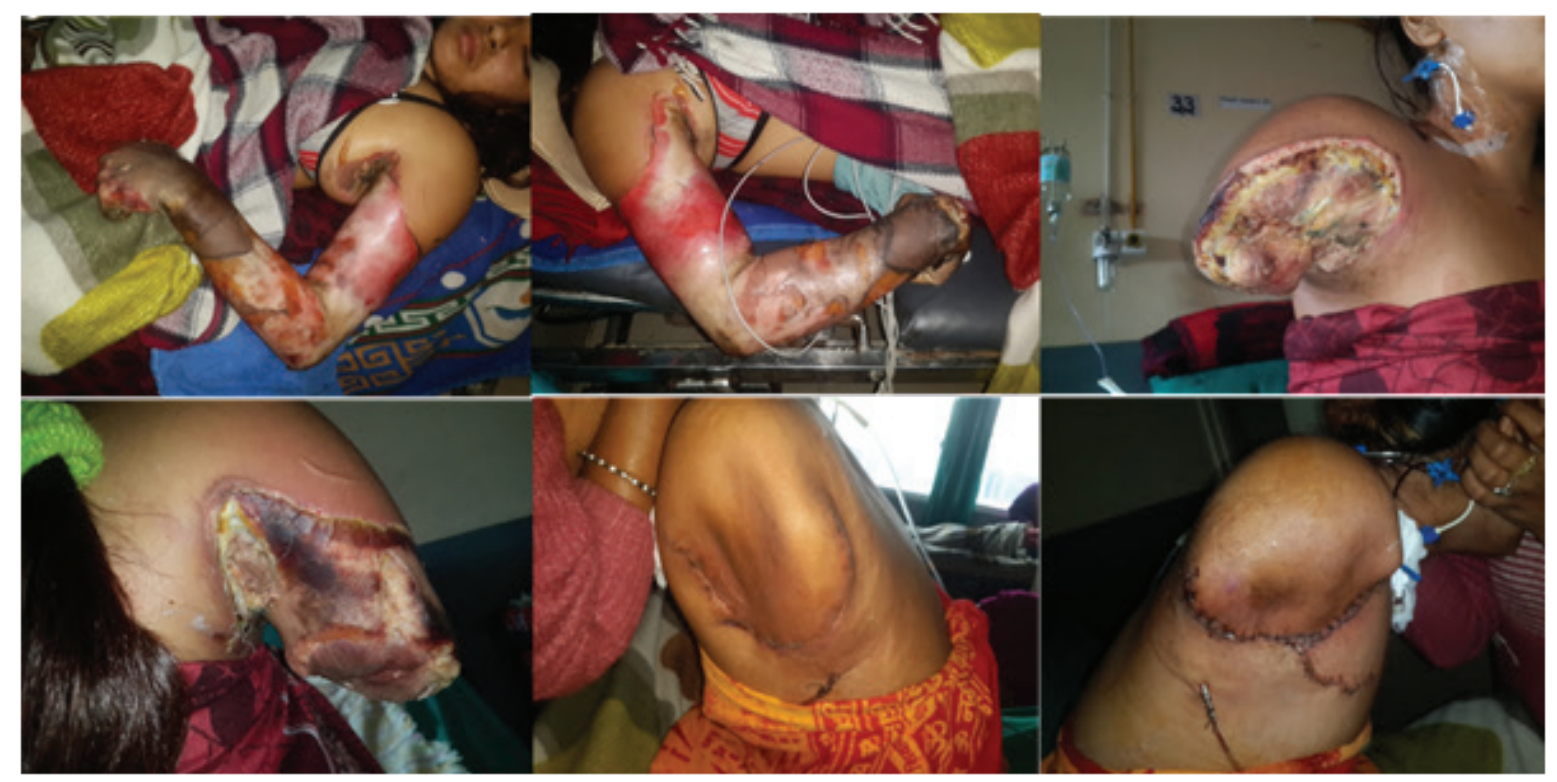

Example 2. This is a young lady of 19 years who sustained household electrical injury over both her upper limbs, where the TBSA was $16 \%$ but presented with necrosis of digits of both hands which later when debrided found to have non-viable deeper tissues up to the shoulder joints on both sides. She later had to undergo both upper limb shoulder disarticulation. Although the wound took more time than usual but ultimately healed.

Internal organ damage is one of the most dreaded of all injuries. A study performed in 1996 on visceral injuries, wound infection, and sepsis following electrical injuries reported only $0.4 \%$ (4) of their patients out of 226 sustained visceral injuries whereas we had $8 \%$ (4). ${ }^{22}$ Other organs like kidneys, structures of the neck like thyroid gland, trachea, larynx, and intestines are also liable to be injured. We had two patients who had associated internal organ injuries. The first one had neck injury where along with the skin, thyroid gland, parathyroid glands, laryngo-tracheal complex were completely necrotic and had tracheostomy done. He, later, underwent bilateral deltopectoral flap coverage. Another patient had intestinal perforation for which he underwent laparotomy and resection and anastomosis.

Bone injuries were assumed to have occurred when nearby structures were completely devitalized as well as the periosteum. All these patients underwent amputations except one who died due to multiple organ failure. In a retrospective study of 700 patients, it is reported to have 22 cases $(3.1 \%)$ of fractures following high-voltage electrical exposure. $^{23}$

High-voltage injuries may largely spare the skin surface but cause massive damage to underlying soft tissue and bone, necessitating escharotomies, fasciotomies, or amputations. ${ }^{19}$ Our findings of very frequent skin damage overall but most of the skin damage occurring within the first category with massive underlying deeper structure injuries suggests that the overlying petty injuries are not to be underestimated and there should be every attempt to rule out any underlying damaged structures.

In a study performed in 1995 in 129 patients reported 323 procedures with an average of 2.5 procedures per patient. ${ }^{24}$ In our study, the possibility of any patient admitted following electrical injury would require on an average 3.8 operative procedures, and if any patient will require any operation then the number of procedure will rise to 4.56 on average. Another finding is that for a given patient the chances of having to undergo operative procedures are $83.33 \%$.

For any given patient, on an overall basis, one might have to undergo all groups of procedures considering his or her extent of injury and that lead to the total operated patient count to 55 , in spite of having only 36 patients in the study. This in turn led to an increased average number of groups of procedures to 2.61 for minor, 2.89 for major and 1.4 for amputations, and thus coming to conclusion that for any given patient, operated or non-operated he or she might have to undergo at least $1.88,1.52$ and 0.38 , minor, major and amputations, respectively. It is very interesting to see how large percentage of patients requires major and amputations 
procedures, $52.77 \%$ and $27.77 \%$. Additionally, majority of the procedures are major and amputations, $40.41 \%$ and $10.21 \%$, respectively. Hussmann et al have reported of performing many procedures from exploratory laparotomy to amputations, where patients with high tension electrical injuries undergoing more procedures per patient.

The first TBSA category has been the most interesting of the groups, where majority all types of management are concentrated. Such a finding is quite intriguing to assimilate where less obvious injury in the form of TBSA exhibits a greater extent of number of procedures required due to greater extent of injury in the deeper tissues. As we can see in figure 10 most of the operated patients fall within the less than or equal to $4 \%$ group. Additionally, median of major procedures in first category is comparable to other groups. Another finding that alarms us is that most of the amputations performed and the patients who underwent amputations fell in to the first TBSA category.

\section{Limitations}

Only admitted patients were studied. No clinical features as well as cardiac complicated patients were accounted in the study. The costs and length of hospital stay have been excluded from the study. The long term sequelae of electrical injuries are not discussed here.

\section{Conclusion}

The true nature of injuries caused by electrical injuries likened to an iceberg phenomenon where on the surface only the tip of the injury can be seen. Realizing this, it may also be very important to acknowledge the gravity of the need to act early if the deeper unrecognized injured structures are to be spared of the consequences of the insult they have sustained and remain unattended that might result in complete loss lest not attempted to save as much that can be possible. Therefore, it might be a necessary procedure, if made as a protocol, to routinely to explore wherever and whenever possible, especially in the extremities and the neck, where vital structures are in the narrowest of the spaces.

\section{References}

1. Kisner S, Casini V: Epidemiology of electrocution fatalities: 1998. In: Worker Deaths by Electrocution: A Summary of NIOSH Surveillance and Investigative Findings. Washington, DC, Department of Health and Human Services (NIOSH), May 1998, pp 9-19. Publication No. 98-131
2. Hiser S: Electrocutions Associated with Consumer Products: Report. Washington, DC: US Consumer Product Safety Commission, Division of Hazard Analysis, Directorate for Epidemiology, July 2001, 1998

3. Casini V: Overview of electrical hazards. In: Wor kerDeathsbyElectrocution:ASummary of NIOSH Surveillance and Investigative Findings. Washington, DC, Department of Health and Human Services (NIOSH), May 1998, pp 5-8. Publication No. 98-131. PMCid:PMC95638

4. Bernstein T: Electrical injury: Electrical engineer's perspective and an historical review. Ann NY AcadSci 1994; 720:1-10. https://doi. org/10.1111/j.1749-6632.1994.tb30430.x

5. Cooper MA: Emergent care of lightning and electrical injuries. SeminNeurol 1995; 15: 268-278 https://doi.org/10.1055/s-2008-1041032, PMid:8570929

6. Lee RC. Physical measurements of tissue injury in electrical trauma. IEEE Trans Education 1991;34:22330. https://doi.org/10.1109/13.85080

7. Lee RC, Gaylor DC, Bhatt D, Israel DA. Role of cell membrane rupture in the pathogenesis of electrical trauma. J Surg Res 1988; 44:709-19. https://doi. org/10.1016/0022-4804(88)90105-9

8. Koumbourlis AC: Electrical injuries. Crit Care Med 2002 Vol. 30, No. 11 (Suppl.). https://doi. org/10.1097/00003246-200211001-00007

9. Fish R: Electric shock: Part I. Physics and pathophysiology. J Emerg Med 1993; 11: 309-312. https://doi.org/10.1016/0736-4679(93)90051-8

10. Jain S, Bandi V. Electrical and lightning injuries. Crit Care Clin 1999; 15:319-331. https://doi.org/10.1016/ S0749-0704(05)70057-9

11. Cooper MA: Electrical and lightning injuries. Emerg Med Clin North Am 1984; 2:489-501 PMid:6534739

12. Cherington $M$ : Central nervous system complications of lightning and electrical injuries. SeminNeurol 1995; 15:233-240. https://doi. org/10.1055/s-2008-1041028, PMid:8570925 
13. WilbournAJ: Peripheral nerve disorders in electrical and lightning injuries. SeminNeurol 15:241255. https://doi.org/10.1055/s-2008-1041029, PMid:8570926

14. Varghese G, Mani MM, Redford JB: Spinal cord injuries following electrical accidents. Paraplegia 1986; 24:159-166. https://doi.org/10.1038/sc.1986.21

15. Kleinschmidt-DeMastersBK: Neuropathology of lightning-strike injuries. SeminNeurol 1995; 15:323328. https://doi.org/10.1055/s-2008-1041039, PMid:8848648

16. Ten DuisHJ, KlasenHJ: Keraunoparalysis, a specific lightning injury. Burns 1985; 12: 54-57 https://doi.org/10.1016/0305-4179(85)90183-4

17. Li H, Yao Z, Tan J, et al. Epidemiology and outcome analysis of 6325 burn patients: a fiveyear retrospective study in a major burn center in Southwest China. Scientific Reports. 2017;7:46066. https://doi.org/10.1038/srep46066, PMid:28383066 PMCid:PMC5382583

18. Sun CF, Lv XX, Li YJ, Li WZ, Jiang L, Li J, Feng J, Chen SZ, Wu F, LiXY. Epidemiological studies of electrical injuries in Shaanxi province of China: a retrospective report of 383 cases. Burns. 2012 Jun;38(4):568-72. https://doi. org/10.1016/j.burns.2011.10.012, PMid:22103989

19. Czuczman AD, Zane RD. Electrical Injuries: A Review For The Emergency Clinician. EB Medicine 2009;11(10)

20. QuinbyWJ, Burke JF, TrelstadRL, Caulfield J. The use of microscopy as a guide to primary excision of high tension electrical burns. J Trauma 1978;18:423-9. https://doi.org/10.1097/00005373-19780600000007

21. SigfridVedung, GöstaArturson, Karin Wadin\& Anders Hedlund (1990) Angiographic Findings and Need for Amputation in High Tension Electrical Injuries, Scandinavian Journal of Plastic and Reconstructive Surgery and Hand Surgery, 24:3, 225-231. https://doi.org/10.3109/02844319009041283 PMid:2281309

22. Haberal M, Ucar N, Bayraktar U, Oner Z, Bilgin N. Visceral injuries, wound infection, and sepsis following electrical injuries. Burns. 1996;22(2):158-161. https://doi.org/10.1016/0305-4179(95)00000-3
23. Arnoldo BD, Purdue GF, Kowalske K, Helm PA, Burris A, Hunt JL. Electrical injuries: a 20-year review. J Burn Care \&Rehabil. 2004;25(6):479-484. https://doi. org/10.1097/01.BCR.0000144536.22284.5C

24. Hussmann J, Kucan JO, Russell RC, et al. Electrical injuries, morbidity, outcome and treatment rationale. Burns 1995;21:530-35. https://doi. org/10.1016/0305-4179(95)00037-C 